University of Nebraska - Lincoln

DigitalCommons@University of Nebraska - Lincoln

$10-1972$

\title{
Herpetomonas megaseliae sp. n. (Protozoa: Trypanosomatidae) from Megaselia scalaris (Loew, 1866) Schmitz, 1929 (Diptera: Phoridae)
}

Pierre M. Daggett

University of Nebraska - Lincoln

John J. Janovy Jr.

University of Nebraska - Lincoln, jjanovy1@unl.edu

Norman R. Dollahon

Villanova University, norman.dollahon@villanova.edu

Follow this and additional works at: https://digitalcommons.unl.edu/bioscijanovy

Part of the Parasitology Commons

Daggett, Pierre M.; Janovy, John J. Jr.; and Dollahon, Norman R., "Herpetomonas megaseliae sp. n. (Protozoa: Trypanosomatidae) from Megaselia scalaris (Loew, 1866) Schmitz, 1929 (Diptera: Phoridae)" (1972). John Janovy Publications. 42.

https://digitalcommons.unl.edu/bioscijanovy/42

This Article is brought to you for free and open access by the Papers in the Biological Sciences at DigitalCommons@University of Nebraska - Lincoln. It has been accepted for inclusion in John Janovy Publications by an authorized administrator of DigitalCommons@University of Nebraska - Lincoln. 


\title{
HERPETOMONAS MEGASELIAE SP. N. (PROTOZOA: TRYPANOSOMATIDAE) FROM MEGASELIA SCALARIS (LOEW, 1866) SCHMITZ, 1929 (DIPTERA: PHORIDAE)*
}

\author{
Pierre M. Daggett, Norman Dollahon, and John Janovy, Jr. \\ Department of Zoology, University of Nebraska, Lincoln, Nebraska 68508
}

ABSTRACT: A new intestinal trypanosomatid was found parasitizing Megaselia scalaris. Forms with posterior kinetoplasts occurred in both natural infections and cloned cultures, but not in experimental infections. Average size and morphological variation were reduced in experimental infections with cloned stocks, compared to natural infections. A growth comparison was made between Herpetomonas muscarum and H. megaseliae. Differences in day of peak population, maximum numbers, and total time of survival were observed in culture. Attempts to infect Drosophila melanogaster with $H$. megaseliae were unsuccessful.

The primary characteristic used to separate Herpetomonas from other genera of insect trypanosomatids is a posterior kinetoplast in up to $40 \%$ of culture forms (Rogers and Wallace, 1971). An intestinal trypanosomatid which exhibited a high percentage of posterior kinetoplasts in culture was discovered in Megaselia scalaris (Loew, 1866) Schmitz, 1929 (see Borgmeier, 1965, for synonyms). The organism was isolated and a study was made of its morphology in culture and in the insect host. In addition, a comparison with Herpetomonas muscarum was made of growth in culture. Morphological and host differences between the newly isolated trypanosomatid and published descriptions indicated that the parasite was an undescribed species of the genus Herpetomonas. The isolate was cloned and the description below is based on cloned material in culture and in experimental infections.

\section{MATERIALS AND METHODS}

Four culture media were used in the study: (1) Mansour's Medium (Dollahon and Janovy, 1971); (2) $1 \%$ proteose-peptone-glucose (PPG); (3) Wallace's Medium (Wallace and Clark, 1959); and (4) A medium consisting of $5 \mathrm{ml}$ Locke's Solution (Tobie et al., 1950) into which one guinea pig fecal pellet was placed (LPG). The LPG was then autoclaved.

The parasites were isolated from the larvae of M. scalaris into Mansour's Medium with $700 \mathrm{mg}$ dihydrostreptomycin and 700 units procaine penicillin-G (Penstrep) per $\mathrm{ml}$. The isolate was cloned 4 times, twice by serial dilution and twice

Received for publication 4 January 1972.

* This study was supported in part by a grant from the University of Nebraska Research Council. by isolation of a single organism with a capillary pipet. Each clone was made from a stock which had been previously cloned. Our present stock has thus been successively cloned 4 times. A combination of 4,000 units of procaine penicillin-G and $5 \mathrm{mg}$ dihydrostreptomycin (Penstrep) per $\mathrm{ml}$ was used in the first transfer after the fourth cloning. A week-old culture in Wallace's Medium, a descendant of the final clone, was used to study the morphology and to describe the trypanosomatid in culture. Cultures were maintained at $25 \mathrm{C}$.

H. muscarum, isolated from Phaenicia sericata, was obtained from Dr. F. G. Wallace, University of Minnesota. It was received in Wallace's Medium and subsequently maintained in our laboratory in Mansour's or Wallace's Medium.

For growth studies, $20 \mathrm{ml}$ of LPG, PPG, or Mansour's Medium was added aseptically to sidearm flasks. A flask of each medium was inoculated with $0.25 \mathrm{ml}$ of a $H$. muscarum culture of the new trypanosomatid. Hemocytometer counts were made on the $3 \mathrm{rd}, 5 \mathrm{th}, 7 \mathrm{th}$, and 10th days after inoculation. Zero time populations were calculated from hemocytometer counts of the inoculum.

Colonies of uninfected host flies, M. scalaris (identification confirmed by Dr. William Robinson, Virginia Polytechnic Institute), were initiated with eggs gathered from guinea pig litter pans. Eggs were washed once in a $1: 10,000$ zephiran-chloride solution and once in distilled water. Washed eggs were placed in 8-oz cotton-gauze-stoppered Frenchquartered bottles containing $50 \mathrm{ml}$ of a Drosophila medium (Strickburger, 1967) which had been modified by the substitution of $250 \mathrm{ml}$ of autoclaved, ground Purina Guinea Pig Chow for $38 \mathrm{ml}$ dried yeast. Uninfected fly colonies were periodically checked for infection. Colonies of infected flies were initiated with larvae from guinea pig litter pans. Drosophila melanogaster, Oregon-R strain, were obtained from Dr. D. D. Miller, University of Nebraska, and were maintained in the same fly medium. The Drosophila were not found to be naturally infected with trypanosomatid parasites.

Insects were infected with culture forms con- 
centrated by centrifugation. Routinely, 2 culture tubes each containing large populations of late log phase organisms ( 1 week after loop transfer) in 5 $\mathrm{ml}$ Mansour's Medium were centrifuged and both pellets resuspended in a total of 3 to $4 \mathrm{ml}$ fresh Mansour's Medium. The fluid was added to the fly bottles and gathered in small depressions in the fly medium. Larvae were observed to feed readily in these areas. No attempts were made to regulate or determine infective doses, although flagellate suspensions prepared as above generally contained at least $10^{7}$ flagellates per $\mathrm{ml}$. Fly bottles contained up to several hundred larvae in all stages of development, as well as adults and pupae.

Morphological studies were based on Giemsastained smears of insect gut contents and smears of the culture forms which had been centrifuged, resuspended in rabbit serum, and stained with Giemsa. Illustrations of stainad material were made with the aid of a camera lucida. In the following description, measurements are in microns. Range is followed by average in parentheses.

\section{Herpetomonas megaseliae sp. $\mathrm{n}$.} (Figs. 1-12)

Parasite in culture (Figs. 1-6) : $N=30$. Sevenday culture in Wallace's Medium. Body short, wide, with short to long flagellum. Usually truncate anteriorly, but occasionally rounded or pointed. Posterior end rounded or pointed. Some biflagellate. Length 8 to 22 ( 13 ); maximum width 4 to 5 (4); flagellum 8 to 30 (14). Nucleus subcircular, 1 to 5 (3) wide, 1 to 4 (3) long. Kinetoplast anterior to nucleus, $67 \%$; lateral, $11 \%$; posterior, $22 \%$.

Parasite in experimental infection (Figs. 7-12): $N=30$. Eighteen days after inoculation of fly colony. In larval intestine, body long, narrow with long flagellum. Most truncate or rounded anteriorly. Posterior pointed. Length 8 to 26 (16); maximum width 1 to 3 (2); flagellum 19 to 44 (28). Nucleus oval, 1 to 2 (1) wide and 1 to 7 (4) long. Kinetoplast $100 \%$ anterior. Infection light in pupae and adults.

Host: Megaselia scalaris (Loew, 1866) Schmitz, 1929 (Diptera: Phoridae).

Site of infection: Throughout intestinal tract of larvae and adults. Undetermined in pupae.

Type locality: Lincoln, Lancaster County, Nebraska.

Type specimens: USNM Prot. Collection No. 63088.

Paratype specimens: USNM Prot. Collection No. 63089. Additional specimens deposited in the Harold W. Manter Laboratory, Division of Parasitology, University of Nebraska State Museum.

\section{Remarks}

The parasite probably occurs in mixed infections in the natural host. All developmental stages of the insect were infected, but natural

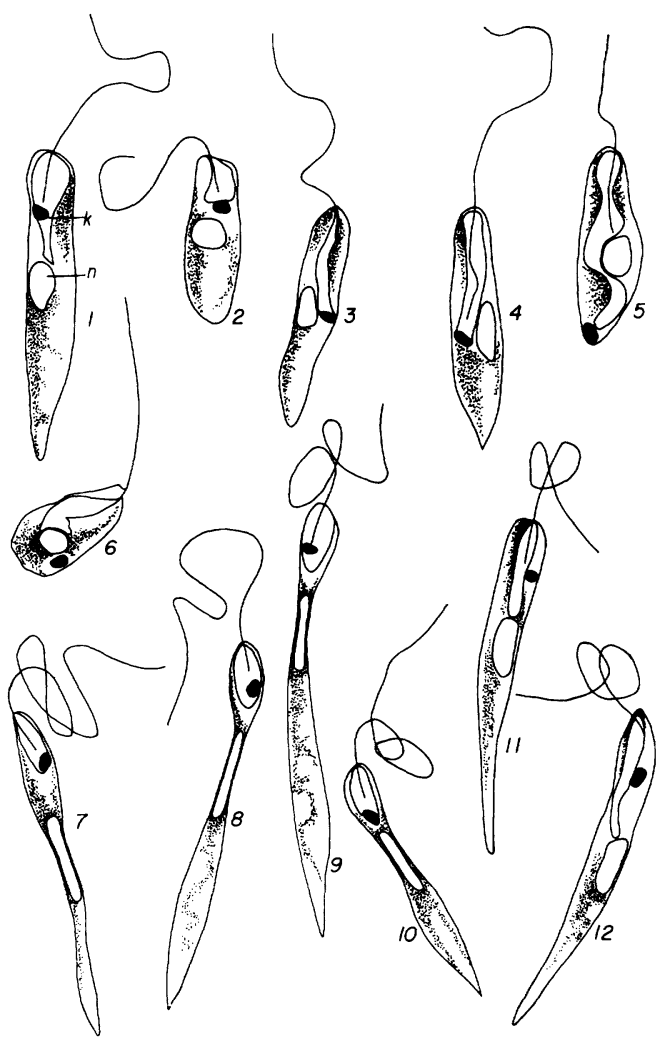

Figures 1-12. Herpetomonas megaseliae. 1-6. Representative forms from 7-day-old culture in Wallace's Medium. Trypanosomatids centrifuged, resuspended in rabbit serum, smeared and stained with Giemsa. 7-12. Representative forms in larvae of experimentally infected Megaselia scalaris (18 days after introduction). Trypanosomatids were mixed in lysed rabbit blood, smeared and stained with Giemsa. $\mathrm{n}=$ nucleus, $\mathrm{k}=$ kinetoplast.

infections tended to be heaviest in the larvae. In the natural infection in larvae only a few rounded or tuncate forms were seen. Most were long and narrow. Occasionally biflagellate forms or forms with a thickened flagellum were observed. The parasites (random selections of all forms $N=30$ ) in natural infections varied from 18 to 48 (29) in length, 1 to 6 (3) in maximum width, with flagellum 14 to 42 (27), and an oval nucleus 2 to 8 (5) by 1 to 4 (2). Kinetoplast position with respect to the nucleus varied from anterior $(96 \%)$ to lateral $(2 \%)$ to posterior $(2 \%)$.

Uninfected M. scalaris were successfully infected experimentally with $H$. megaseliae at each attempt. Experimental infections were 
TABLE I. Growth of Herpetomonas muscarum and H. megaseliae in three media. Numbers represent organisms per $m l$ (average of two counts per day). Day zero numbers calculated from hemocytometer counts of inoculum.

\begin{tabular}{|c|c|c|c|c|c|}
\hline & \multicolumn{5}{|c|}{ Day } \\
\hline & 0 & 3 & 5 & 7 & 10 \\
\hline \multicolumn{6}{|l|}{ PPG } \\
\hline H. muscarum & 22,500 & 175,000 & 225,000 & 300,000 & 0 \\
\hline H. megaseliae & 3,500 & 75,000 & 75,000 & 675,000 & 750,000 \\
\hline \multicolumn{6}{|l|}{ LPG } \\
\hline H. muscarum & 22,500 & $3,400,000$ & $2,450,000$ & $3,200,000$ & $2,975,000$ \\
\hline H. megaseliae & 3,500 & 50,000 & 250,000 & $1,800,000$ & $2,675,000$ \\
\hline \multicolumn{6}{|c|}{ Mansour's Medium } \\
\hline H. muscarum & 22,500 & $5,750,000$ & $16,000,000$ & $13,500,000$ & $8,750,000$ \\
\hline H. megaseliae & 3,500 & $3,000,000$ & $52,750,000$ & $31,250,000$ & $48,250,000$ \\
\hline
\end{tabular}

maintained in the colony and through subsequent transfers of the flies to fresh media. Experimental infections tended to be lighter than natural infections in all host stages.

Attempts to infect $D$. melanogaster larvae with $H$. megaseliae were not successful. Parasites were active in the anterior portion of the larval gut only up to $48 \mathrm{hr}$.

Growth in culture: The growth of $H$. megaseliae differed considerably from that of $H$. muscarum in the three different media (Table I). In two media, H. megaseliae reached higher numbers than H. muscarum and continued growing after the latter organisms were declining. Peak populations in PPG declined with succeeding transfers in that medium. Longest term survival was in LPG. H. megaseliae survived 200 days in a flask containing $20 \mathrm{ml}$ of LPG; H. muscarum survived 84 days.

Culture morphology: The organisms in culture bore some resemblance to those pictured in the original description of Crithidia luciliae. Strickland (1911) presented illustrations of parasites from the "oesophageal diverticulum," from the "midgut and small intestine," and "hindgut and rectum." Wallace and Clark (1959) stated that Strickland was observing a mixed infection, and separated Strickland's description into $H$. muscarum ("forms in the midgut") and C. luciliae ("oesophageal diverticulum and rectum"). Three of the 15 flagellates in Strickland's plate VIII (figs. 7-22, "forms from the hindgut and rectum") have posterior kinetoplasts. However, forms with a kinetoplast posterior to the nucleus were excluded from $C$. luciliae for both infections and culture by Wallace and Clark (1959). In our stocks of $C$. luciliae from the American Type Culture Collection, in 7-day-old cultures in Wallace's Medium, we have not observed forms with posterior kinetoplasts. Researchers using these original descriptions of insect trypanosomatids (Strickland, 1911), as amended by Wallace and Clark (1959), should be aware of this difference between what Strickland illustrated as representative of "hindgut and rectum" parasites and the present American Type Culture Collection stocks of $C$. luciliae.

\section{DISCUSSION}

H. megaseliae, dimensionally and in the percentage of culture forms with posterior kinetoplasts, is within the range reported for $H$. muscarum (Rogers and Wallace, 1971). However, growth in the three media indicates that the two are quite different physiologically.

In $H$. megaseliae, the presence of a truncate anterior end, a wide reservoir, and few biflagellate forms in both culture and experimental infections are not generally characteristic of previously described Herpetomonas. These characteristics tend to resemble those of Crithidia, but Rogers and Wallace (1971) have shown in their study that tendencies toward these characteristics occur in opisthomastigote forms of $H$. muscarum. However, the distinctive generic character is the presence of a postnuclear kinetoplast, which is restricted to Herpetomonas. 
It is perhaps characteristic of the problems of trypanosomatid taxonomists that a shift in the nature of a taxonomic character can occur between two environments. The proportion of individuals of $H$. megaseliae with posterior kinetoplasts was observed at $22 \%$ in culture, but that proportion was reduced to zero when the cloned stocks were introduced into uninfected flies (see taxonomic section above). Thus, in the present study, the Herpetomonas generic character disappeared when the new species was reintroduced into its natural host. A comparison of the natural and experimental infections indicated that the natural infections may have been a mixture of the new species and another undescribed species. Average size and percentage of posterior kinetoplasts in the natural hosts were both reduced by the cloning process.

The culture media used were selected for several reasons. Dollahon and Janovy (1971) observed trypanosomatids in the urine and feces in guinea pig litter pans. LPG was used in an attempt to approximate these conditions. The long survival of both $H$. megaseliae and $H$. muscarum indicate that similar natural conditions may facilitate distribution of these parasites. Since H. muscarum was most recently redescribed from Wallace's (Wallace ana Clark, 1959), H. megaseliae was described from the same medium. PPG was used as a simplified medium for comparative growth. Mansour's is the medium in which trypano- somatids are normally maintained in our laboratory.

\section{ACKNOWLEDGMENTS}

The authors are indebted to Dr. F. G. Wallace, Department of Zoology, University of Minnesota, for a stock culture of Herpetomonas muscarum; to Dr. D. D. Miller, University of Nebraska, for the stock of Drosophila melanogaster; and to Dr. William Robinson, Virginia Polytechnic Institute, for aid in identification of the dipteran host, Megaselia scalaris.

\section{LITERATURE CITED}

Bongmeier, T. 1965. Revision of the North American phorid flies Part III. The species of the genus Megaselia, subgenus Megaselia (Diptera, Phoridae). Stud. Ent. 8: 1-160.

Dollahon, N., AND J. Janovy, Jr. 1971. Insect flagellates from feces and gut contents of four genera of lizards. J. Parasit. 57 : 1130-1132.

Rogers, W. E., and F. G. Wallace. 1971. Two new subspecies of Herptomonas muscarum (Leidy, 1856) Kent, 1880. J. Prot. 18: 645649.

Strickburger, M. W. 1967. Experiments in Genetics with Drosophila. 6th ed., John Wiley and Sons, Inc., New York, 144 p.

Strickland, C. 1911. Description of a Herpetomonas parasitic in the alimentary tract of the common green bottle fly, Lucilia sp. Parasitology 4: 22-236.

Tobie, E. J., T. von Brand, and B. Mehlman. 1950. Cultural and physiological observations on Trypanosoma rhodesiense and Trypanosoma gambiense. J. Parasit. 36: 48-54.

Wallace, F. G., and T. B. Clark. 1959. Flagellate parasites of the fly, Phaenicia sericata. J. Prot. 6: 58-61. 